\title{
CRIZA CORPORALITĂȚII ÎN POETICA LUI ILARIE VORONCA
}

\section{Alexandru Foitoș Universitatea de Vest din Timișoara}

Abstract: The aim of this paper is to highlight the vanguardist poetical universe of Ilarie Voronca, focusing on the construction of corporeal representations. The poetics of corporeality is associated with the concept of "crisis", the latter being reverberated in the vanguard lyrical works as an effect of the historical and social context of the $20^{\text {th }}$ century, which is the First World War. As a result, the consequences of this context bring to the vanguard writers poetical substance, which encapsulates the body and the disease, these two being transposed into several eerie, radical and shocking images in Ilarie Voronca's poetics. This paper is going to demonstrate the existence of several corporeal representations in Ilarie Voronca's poems, which are mainly represented by the vulnerable body, viewed as a limit and as the diseased/the suffering, proving that the crisis of corporeality is the effect of the historical conflagration at the beginning of the $20^{\text {th }}$ century.

Cuvinte cheie: corporalitate, criză, maladivul, avangardă, alienare Key-words: corporeality, crisis, the diseased, vanguard, alienation

Contextul secolului XX a reprezentat pentru avangarda românească una dintre cauzele majore ale reverberării unor imagini radicale în universul poetic al unor autori precum Ilarie Voronca, Geo Bogza, Tristan Tzara, Gherasim Luca sau Virgil Teodorescu. Efectele Primului Război Mondial, printre care și „experiența corporală [...] care s-a tradus printr-o mortalitate în masă", au dus la intensificarea unei crize care s-a manifestat indubitabil și în plan poetic. Perioadă marcată de „evenimente grave ale războiului, cu consecințele sale dezastruoase și haotice [...] care vor declanșa o revoltă latentă, dezvoltând-o până la limitele extreme"2, ea va duce la manifestarea unei neliniști existențiale în poeziile scriitorilor avangardiști, printre care și în universul poetic al lui Ilarie Voronca, cel care va reprezenta figura centrală a analizei.

Lucrarea de față își propune să observe modul în care criza corporalității se manifestă în poeziile lui Ilarie Voronca, aceasta fiind generată de consecințele conflagrației de la începutul secolului al XX-lea, întrucât ele

\footnotetext{
${ }^{1}$ Alain Corbin, Jean-Jacques Courtline, Georges Vigarello, Istoria corpului, III, trad. din franceză de S. Manolache, M. Arnat, M. Constantinescu, G. Sfichi, Grupul Editorial Art, București, 2009, p. 490.

${ }^{2}$ Ion Pop, Avangardismul poetic românesc, Editura pentru literatură, București, 1969, p. 153.
}

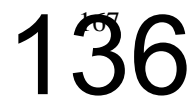


au adus material de studiu al ieșirilor din firesc pentru poeții avangardiști români şi la concentrarea unor noi imagini poetice. În volumul al III-lea realizat de Alain Corbin, Jean-Jacques Courtline și Georges Vigarello se afirmă că „orice experiență de război este înainte de toate o experiență a corpului. În război, corpurile exercită violență și tot ele o îndură"3. Astfel, ororile Primului Război Mondial ,,au avut răsunete în imageria artistică", răsfrângându-se în diferite modalităţi de manifestare a crizei corporalităţii, precum crearea unor reprezentări „dezmembrate, dezarticulate, mutilate, chipuri desfigurate și masacrate" ${ }^{, 5}$ ale acesteia.

Observăm, aşadar, o ruptură violentă faţă de tot ce înseamnă tradiție și sistem de convenții la nivelul poeticii, adică așa cum afirmă și Marin Mincu, se realizează o „schimbare profundă în modul de a concepe și de a structura obiectul literaturii”’ . Atenţia cade acum și asupra corporalităţii, aceasta fiind surprinsă prin stări conflictuale, prin „,crize, drame și experienţe personale” ${ }^{7}$ și care se află acum în prim plan poetic.

Ilarie Voronca surprinde aspectele anterior menţionate în textul programatic Suprarealism și integralism din 1925, în care afirmă că „,de la război mai ales, Europa a trecut prin frământări continue" 8 , astfel încât putem deduce și observa conștientizarea influenței conflagrației mondiale în textele sale poetice, prin ,nenumăratele suferințe pricinuite de tragedia sângeroasă a violențelor secolului XX" ${ }^{\prime 9}$. De aceea, universul poetic voroncian prezintă un întreg spectacol al corpului omului modern, prin ,imagini scandaloase sau exhibiţioniste" ${ }^{10}$ surprinse în textele poetice.

Obsesiile corpului şi ale maladivului au reprezentat constante în literatura română, referindu-ne la mișcarea anterioară avangardei, și anume la simbolism, de unde provin și majoritatea viziunilor stridente ale corporalităţii. Acestea sunt transferate în universul poetic al scriitorilor avangardiști, fiind influențaţi în perioada de tinerețe a creației lor de acest curent, prin apetența pentru radicalizarea imaginilor și a limbajului, pentru „spleenul simbolist, iritarea nevrotică, ca efect al unor trăiri precizate, ca boala, singurătatea, monotonia etc."11. Atmosfera preavangardistă din spațiul românesc este, astfel,

\footnotetext{
${ }^{3}$ Alain Corbin, Jean-Jacques Courtline, Georges Vigarello, op. cit., p. 329.

${ }^{4}$ Ibidem, p. 490.

${ }^{5}$ Ibidem.

${ }^{6}$ Marin Mincu, Avangarda literară românească, Editura Minerva, București, 1983, p. 5.

${ }^{7}$ Marino, Adrian, Biografia ideii de literatură, volumul 6, Editura Dacia, Cluj-Napoca, 2000, p. 168.

${ }^{8}$ Marin Mincu, op. cit., p. 566.

${ }^{9}$ Alain Corbin, Jean-Jacques Courtline, Georges Vigarello, op. cit., p. 9.

${ }^{10}$ Sașa Pană, Antologia literaturii române de avangardă, Editura pentru literatură, București, 1969, p. 17.

${ }^{11}$ Marian Victor Buciu, Panorama literaturii române în secolul XX, I, Editura Scrisul Românesc, Craiova, 2003, p. 24
} 
antrenată de simbolism, influența căruia se resimte în primele poeme scrise de Ilarie Voronca, Tristan Tzara sau Ion Vinea.

Dacă în critica literară se amintește deseori de conturarea unui „imagism” specific lui Ilarie Voronca, prin surprinderea peisajelor într-o manieră proprie, reprezentările corporalului în opera sa poetică sunt, de asemenea, predominante. Acestea se realizează printr-o terminologie anatomică utilizată și care se manifestă prin constituirea corpului vulnerabil, adică cel care înglobează valențe precum corpul ca limită și corpul suferind/maladiv. Descrierile anatomice le regăsim atât la Ilarie Voronca, precum și la alți scriitori avangardiști români. Însă, vorbim în cazul acestora despre o „restructurare a percepției asupra corpului” ${ }^{12}$, întrucât observăm cum se realizază trecerea de la concepția unui „,corp armonios şi simetric al Antichității și, respectiv, renascentist, la cele dislocate și dezmembrate ale avangardei" ${ }^{3}$. Corpul, deși aflat în criză, este spectacularizat şi oferit lectorului spre crearea unui câmp vizual cât mai surprinzător și cât mai radical.

Ilarie Voronca ,nu mai aderă la imaginea poetică tradiţională, marcată de ordine, armonie și echilibru, tocmai pentru că o astfel de imagine e resimțită ca falsă, idilică și convențională. Poetul apelează, dimpotrivă, la imaginea convulsivă, asimetrică, sfărâmând armonia idilizantă a versului tradițional" ${ }^{\prime 4}$, iar materialul poetic asimilat prin efectele războiului denotă, în cadrul poeticii voronciene, o, ,experiență agonistică ${ }^{15}$ a corpului care poate să fie maladiv și suferind, frământat neliniște.

Criza corpului devine spectacularizată în poeziile avangardiștilor și, în special, în cele ale lui Ilarie Voronca, conturând ,trecerea ființei prin toate locurile întunecate ale trupului marcat de suferință" ${ }^{\prime \prime}$. Astfel de crize sunt specifice modernităţii și le putem regăsi și în romanele lui Max Blecher, în nuvela Metamorfoza a lui Franz Kafka, precum și în Muntele vrăjit al lui Thomas Mann. Secolul al XX-lea devine, astfel, obsedat de problema trupului şi a bolii totodată. Acestea sunt transformate în metafore de natură radicală, iar efectul lor este reprezentat de procesul de alienare a ființei. Atât în aceste texte fundamentale ale modernismului, cât şi în poetica lui Ilarie Voronca, identificăm imaginea corpului vulnerabil aflat în criză, acesta fiind doar „, siluetă nesigură" 17 care duce la conturarea unei metafore a alienării, prin „dispariția subită a identității” ${ }^{18}$ și prin teama de neregăsire. Corpul omului

\footnotetext{
${ }^{12}$ Lucia Simona Dinescu, Corpul în imaginarul virtual, Editura Polirom, Iași, 2007, p. 8.

${ }^{13}$ Ibidem, p. 7.

${ }^{14}$ Iulian Boldea, Simbolism, modernism, tradiționalism, avangardă, Editura „Aula”, Brașov, 2002, p. 14.

${ }^{15}$ Marin Mincu, Experimentalismul poetic românesc, Editura Paralela 45, Pitești, 2006, p. 36.

${ }^{16}$ Gabriela Glăvan, Viraj în ireal. Modernități particulare în literatura română interbelică, Editura Universității de Vest, Timișoara, 2014, p. 119.

${ }^{17}$ Max Blecher, Întâmplări în irealitatea imediată, Editura Minerva, București, 1970, p. 5.

${ }^{18}$ Ibidem, p. 7.
}

\section{8}


modern, alienat fiind, devine o carapace, un obstacol, înăuntrul căruia ,tot ce e capabil să se agite [...], se agită, se zbate și se revoltă mai puternic și mai elementar decât în viața cotidiană"19.

Reprezentarea principală a corporalității în poetica lui Ilarie Voronca se realizează prin imaginea corpului vulnerabil și care înglobează corpullimită şi cel maladiv/suferind. Imaginea acestora generează o criză a eului care se regăsește între exterior și interior, în sensul în care un corp vulnerabil are parte de o „traumă ontologică "20, deci de o neliniște existențială interioară. Se realizează, aşadar, un conflict între „,eea ce este corporal, care este simțit și nu perceput" ${ }^{21}$, adică exteriorul, respectiv crizele și pulsiunile interioare ale unei existențe incerte, imaginea centrală a analizei de față devenind o ,închisoare a minții și a sufletului’"22. Vulnerabilitatea mai poate fi surprinsă prin anumite presiuni exterioare care denotă acte de violență și agresivitate și care se răsfrâng asupra corpului, acesta devenind suferind.

Observăm la Ilarie Voronca imaginea trupului vulnerabil în Brățara nopților, și anume în secvența I, prin versurile „Iată un șarpe se târăște peste pleoapele noastre/Un țipăt clatină ca ulmi umerii/Durerile, ce nămol, ne sug tălpile/Frații mei frații mei știu foamea și suferința voastră/De câte ori am vrut să vă dau un ospăț somptuos din inima și plămânii mei”"23. Există o asociere a elementelor anatomice în fiecare vers cu reprezentări tranşante și radicale, precum țipătul, durerea tălpilor, fragilitatea umerilor, foamea și suferința, acestea contribuind la generarea crizei corpului vulnerabil. Prezența metaforei „şarpelui” și a „nămolului” alături de elementele anatomice schițează un corp urât, respingător şi grotesc prin bizareria asocierii imaginilor, un trup „scufundat în noroi” ${ }^{24}$. Durerea și suferința corpului duc la o „,criză identitară conectată unei stări precare a ființei, aflată sub semnul unei continue amenințări a disoluției și morții”,25.

În secvența a II-a din Brățara nopților, regăsim versurile „Umerii cărbunarilor se macină în docuri/De cărbune e sângele lor ca scorburile trăsnite/Și şlepurile înghit cu sacii ultimele rămășițe ale surâsului/Trupurile se veștejesc ca lămpile frunzelor" ${ }^{26}$ care trimit spre un context social în care munca istovitoare este cea care constrânge și apasă cu o greutate semnificativă

\footnotetext{
${ }^{19}$ Ibidem, p. 6.

${ }^{20}$ Alexandru Mușina, Paradigme moderne, Editura „AULA”, Brașov, 2004. p. 106.

${ }^{21}$ Alina-Daniela Ciric, Corporalitate și intersubiectivitate, Editura Academiei Române, ClujNapoca, 2015, p. 49.

${ }^{22}$ Hortensia Pârlog, Pia Brînzeu, Aba-Carina Pârlog, Translating the body, Institutul European, Iași, 2009, p. 9. Traducerile din limba engleză îmi aparțin.

${ }^{23}$ Ilarie Voronca, Ulise. Brățara nopților, ediție îngrijită de Ion Pop, Editura Dacia, Cluj-Napoca, 2003 , p. 45.

${ }^{24}$ Gabriela Glăvan, op. cit., p. 141.

${ }^{25}$ Ibidem, p. 161.

${ }^{26}$ Ilarie Voronca, op. cit., p. 50.
}

\section{9}


asupra corpului. Precum în secvența anterioară, observăm preferința pentru imaginea anatomică a „umerilor”, sugestie a unei false voințe și stăpâniri de sine, întrucât remarcăm utilizarea formei verbale „se macină” și care denotă agresivitatea, violența asupra unui corp vulnerabil. Repetitivitatea agresiunii asupra trupului rezultă în ceea ce sugerează versul „Trupurile se veștejesc ca lămpile frunzelor" ${ }^{27}$, și anume un proces continuu de degradare a corpului, omul cunoscând ceea ce înseamnă limita absolută a condiției umane.

Figura trupului supus agresiunii se regăsește și în secvența a X-a din Zodiac, prin versurile „Ochiul rupe de pe piept carnea ca pe o maladie nemeritată/Și-arată cum rod viermii și poftele-n dedesupturi”28. Observăm modul în care corpul vulnerabil și chinuit este spectacularizat prin aglomerarea unor imagini ce sugerează desfigurarea sa şi prin verbele care denotă violența, precum „rupe” și „rod”. De asemenea, lexicul utilizat este cel care generează o senzație de neliniște, de angoasă, ca de pildă prezența viermilor și cea a cărnii „rupte de pe piept”. Tot în această secvenţă, versurile „E o fiinţă străină care se ridică în vârful degetelor tale/Care se-așează-n carne și îți îmbracă pe dinăuntru trupul/Îți trece o mână prin pletele coastelor și-ți scoate inima"29 conturează imaginea unei pătrunderi în dimensiunea interioară a corpului. Utilizarea formelor verbale „se ridică”, „se-așează”, „îți îmbracă”, „îți trece” sugerează neutralitate și denotă o falsă gestică erotică. Ele reliefează o ,gestică de torturat" ${ }^{30}$ ce culminează cu eviscerarea organului central, inima, de către o „ființă străină”, adică vorbim despre un corp vulnerabil în faţa unei acțiuni exterioare inevitabile. Acesta este, astfel, dezumanizat și devine doar „,arne și materie organică ${ }^{, 31}$, unitatea sa fiind fragmentată. Mai mult, corpul devine o limită, un obstacol în versul "Și-această întemnițare a omului într-însul,",32, rezultând o amplificare a neliniștii ființei, a crizei interioare care este păstrată în trupul-închisoare.

În secvența a VI-a din Petre Schlemihl regăsim sugestia unui corp supus torturii, prin versurile „Ah! Ce bine mi-au făcut pietrele pe care mi le-aţi aruncat/Și ocările și scuipatul vostru ca niște haturi ale solitudinei/Prin huiduieli, în aer, țesute-n curcubeie/Tristețea subțiată pe inima-nicovală.",33. Sugestie a unui proces de reificare a umanului, observăm o asemănare cu nuvela Metamorfoza a lui Franz Kafka, în care membrii familiei lui Gregor Samsa agresează corpul vulnerabil al protagonistului. La fel și în Petre

\footnotetext{
${ }^{27}$ Ibidem.

${ }^{28}$ Ilarie Voronca, Poeme alese, I, traduceri și prefață de Sașa Pană, Editura Minerva, București, 1972, p. 107.

${ }^{29}$ Ibidem.

${ }^{30}$ David Le Breton, Antropologia corpului și modernitatea, trad. de Doina Lica, Editura Amacord, Timișoara, 2002, p. 52.

${ }^{31}$ Gabriela Glăvan, op. cit., p. 163.

${ }^{32}$ Ilarie Voronca, op. cit., 1972, p. 107.

${ }^{33}$ Ibidem, p. 153.
}

\section{0}




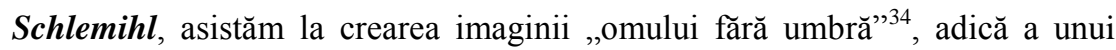
corp fără substanță, irelevant pentru ceilalți, ostracizat, reprezentând doar simpla condiție de om disprețuit la nivel social, un om fără noroc. Violența fizică asupra corpului este cea care generează solitudinea și alienarea omului, adică o criză interioară marcată de ,incertitudine, ambiguitate, vidul existențial” ${ }^{\prime 3}$. Acestea se amplifică în continuare, prin versurile „,M-ați alungat de pe ulițele pline de vuiet,/M-ați lovit cu bice în piețele publice ca pe un cal bătrân"36. Înjosirea omului se realizeză prin violența amplificată, întocmai precum în versurile anterior analizate, regăsind un joc între corpul uman și cel animal. Violența este însă repetitivă și obsesivă, așa cum putem observa în sintagmele ,Știam că pe fața mea lacrima, cicatrice, $/ \mathrm{Nu}-1$ va face să șovăie pe acel care mă va lovi mâine;"’37. Tensiunea lăuntrică a omului atinge punctul culminant, fizicul este epuizat, iar ,angoasele făpturii hăituite”38 erup, toate acestea creând o corporalitate vulnerabilă și chinuită.

Secvența a VII-a înglobează o multitudine a detaliilor anatomice, aşa cum surprind versurile „Dar să vă spun: chiar dacă m-ați răscoli până în cele mai adânci măruntaie,/Cum ai sparge o vioară ca să găsești în ea cântecul” ${ }^{\text {"39 }}$ și „Cu sufletul care-n carne, ca-ntr-o cămașă de forță,/Se zvârcolește, zgârie, ar vrea să se elibereze," ${ }^{40}$. Aceste versuri ne amplasează în interioritatea fizică a corpului ce devine un impediment, iar verbele utilizate, ,ai sparge”, „se zvârcolește”, ,zgârie”, sugerează aceeași agresivitate, violență și radicalizare precum în celelalte opere poetice analizate. În acest caz observăm corpul care devine un obstacol, o limită a omului închis într-o carapace, în care sufletul este captiv și nu poate să aibă parte de exteriorizarea pulsiunilor interioare. Corpul-limită se regăsește și în secvența a XIII-a, prin versurile „Și e aici sau e acolo, un om grăbit să ajungă la o limită,/Și el nu știe: această limită e în el"41, care sugerează un eu poetic prins în propria sa carapace, precum un Gregor Samsa kafkian, fără posibilitatea de a se putea descătușa de constrângeri, de propriile pulsiuni și, de fapt, de criza interioară care devine una a corpuluilimită.

În Patmos și alte șase poeme, poezia Aceste mâini concentrează imaginea unui corp vulnerabil în fața naturii, versul cel mai sugestiv fiind

\footnotetext{
${ }^{34}$ Al. Piru, Istoria literaturii române, Editura „Grai și suflet - cultura națională”, București, 1994, p. 258.

${ }^{35}$ Marian Victor Buciu, op. cit., p. 27.

${ }^{36}$ Ilarie Voronca, op. cit., 1972, p. 153.

${ }^{37}$ Ibidem.

${ }^{38}$ Ion Pop, A scrie și a fi. Ilarie Voronca și metamorfozele poeziei, Editura Cartea Românească, București, 2007, p. 19.

${ }^{39}$ Ilarie Voronca, op. cit., 1972, p. 155.

${ }^{40}$ Ibidem.

${ }^{41}$ Marin Mincu, op. cit., 1983, p. 151.
} 
„Trupul lovit în spasmuri de stâncile tenebre" ${ }^{42}$. Observăm un conflict între corporalitate și materialitate, antrenat de utilizarea termenului „lovit”, denotând violența și agresivitatea naturii copleșitoare asupra dimensiunii tactile a corpului, dar şi asupra perisabilității și a fragilității omului. Imaginea conturată în versul supus analizei realizează o ,transpunere halucinantconcretă a procesului de reificare a omului" "43, corpul ființei umane devenind doar un obiect precis ce poate fi supus unor presiuni exterioare. Un aspect similar se află şi în poezia Mai sunt aici? din Permis de şedere, unde regăsim versurile „Corpul e deja precum o navă ce se cufundă,/Un colac de salvare, vocea mea -/Va mai pluti un timp. Dar nimeni nu vede,/Și nimeni nu aude chemarea..." ${ }^{\prime 4}$. Corpul vulnerabil devine un simplu obiect distrus de data aceasta de elemente ale acvaticului, iar ultimele două versuri sugerează alienarea ființei umane, în special surprinsă prin utilizarea unei serii de negații, fiind reprezentată de formele verbale negative „nu vede”, „nu aude” și de pronumele negativ ,nimeni”.

Tot în Mai sunt aici? observăm versurile: „Și poetul trebuie să simtă mult timp lanţurile/Și astfel în carne trebui să fermenteze,/- Înainte de a se elibera și să poată cutreiera/Meleagurile voastre, cuvintele voastre - sufletul acestor/întunecimi/Ale cărnii, pe care o făcu să sufere și ale acestor buze/Pe care le făcu încă mai palide decât florile/Care devin fructe. Corpul plin de dureri/Nu va fi mai matur decât după o suferință extremă/Ca să elibereze acest chip pur al poemei,/Sufletul aruncând carnea cum arunci o unealtă/Când ai terminat lucrul.../La ce bun această unealtă" ${ }^{\prime 5}$. Suferința transmisă prin intermediul versurilor este accentuată de prezența „lanțurilor”, acestea sugerând în mod direct corpul ca un impediment spre descătuşare, spre capacitatea ființei umane ,de a se elibera”. Precum un trup rănit în război, imaginea cărnii intrate în stare de putrefacție conturează o „corporalitate afectată [...], frecvent incapabilă de a-și recupera integritatea. Rănită și redusă la tăcere" ${ }^{46}$. Așadar, poetul, cel capabil de sacrificu pentru a-şi realiza propria creație, are parte de un proces îndelungat de agonie, sugestie a sintagmelor „trebuie să simtă mult timp”, dar orice experiență-limită a corpului chinuit îl poate face mai viguros, mai „matur”, deși este văzut doar ca o bucată de carne sau ca o unealtă nefolositoare, întocmai precum personajul lui Max Blecher din Intâmplări în irealitatea imediată își simțea „senzația bizară de inutilitate" ${ }^{\text {" }}$. Suferința este, aşadar, în poetica lui Ilarie Voronca, o obsesie

\footnotetext{
${ }^{42}$ Ilarie Voronca, op. cit., 1972, p. 200.

${ }^{43}$ Sașa Pană, op. cit., p. 22.

${ }^{44}$ Ilarie Voronca, op. cit., 1972, p. 241.

${ }^{45}$ Ibidem, p. 243.

${ }^{46}$ Hortensia Pârlog, Pia Brînzeu, Aba-Carina Pârlog, op. cit., p. 58.

${ }^{47}$ Max Blecher, op. cit., p. 8.
} 
care devine o boală. De aceea, putem considera valența corp maladiv/suferind în analiza de faţă ca fiind complementară.

Interesul pentru maladiv la Ilarie Voronca debutează încă din perioada în care acesta utilizează cuvinte aleatorii și automate cu scopul de a destructura textul poetic, aspect binecunoscut și la alți scriitori avangardiști. Spre exemplu, printre termenii înșirați ai poeziei Semnalizări, identificăm asocieri ale unor afecțiuni ale „trupului în aer înșurubat"48 cu elemente tradiționale, familiare lectorului. Automatismul și aleatoriul creează imagini tranșante pentru cititor, precum următoarele sintagme: „tristă meningita"49, „anevrism elegant”,50, „solfegiată nevralgia", ș1 „miopia vitrinelor" ${ }^{\text {, } 52}$. Maladivul în această poezie este coborât în derizoriu și reprezintă un prim pas spre utilizarea lui ca material poetic în textele poetice ale mișcărilor de avangardă, în plin secol XX marcat și obsedat de ,experiența bolii [...], diluată sub forma unei angoase de niște suferinţe" ${ }^{, 53}$.

În secvența a II-a din Ulise remarcăm sugestii cu privire la maladiv, în versurile: „CEAI cae desfeți limba și măruntaiele/CEAI care micşorezi bolnavilor suferința/ierburi sălbatice din noi răutatea oamenilor taie-le/adu în ficatul și în rărunchii mei liniștea umilința" ${ }^{54}$. Sintagma „micșorezi bolnavilor suferința" sugerează, precum în alte poezii analizate, faptul că suferința este o boală a corpului vulnerabil aflat în criză, întrucât „,maladiile sunt, simultan, fenomene biologice obiective și stări, moduri personale a de a fi ",55. A fi suferind și, implicit, a avea un corp suferind reprezintă stări care denotă o corporalitate maladivă, individul fiind dependent la nivel fizic de aceasta.

Concluzionând, suferința devine o boală obsesivă în scrierile lui Ilarie Voronca, cât și în operele altor autori avangardiști şi este complementară percepției corpului ca obstacol, ca limită. Suma acestora realizează reprezentarea corpului vulnerabil aflat în criză și care este supus unor presiuni exterioare. Scriind într-o perioadă aflată în criză în toate planurile, inclusiv în cultură, politică, economie și în plan social, avangardiștii încearcă să transforme radical anumite fundamente culturale considerate tradiționale. Unul dintre aceste fundamente este corpul. Secolul al XX-lea este preocupat de obsesia bolii și a suferinței asupra corpului, iar efectele conflagrației mondiale se răsfrâng în textele avangardiste, printre care și în cele ale lui Ilarie Voronca.

\footnotetext{
${ }^{48}$ Marin Mincu, op. cit., 1983, p. 134.

${ }^{49}$ Ibidem.

${ }^{50}$ Ibidem.

${ }^{51}$ Ibidem.

${ }^{52}$ Ibidem.

${ }^{53}$ Alain Corbin, Jean-Jacques Courtline, Georges Vigarello, op. cit., p. 14.

${ }^{54}$ Ilarie Voronca, op. cit., 2003, p. 18.

${ }^{55}$ Alain Corbin, Jean-Jacques Courtline, Georges Vigarello, Istoria corpului, I, trad. din franceză de S. Manolache, G. Puica, M. Constantinescu, G. Sfichi, Grupul Editorial Art, București, 2008, p. 407.
}

$$
143
$$


Scriitorii avangardişti caută să redea și să se exprime printr-un limbaj adecvat prezentului, în rezonanță cu acele „crize profunde pe care le traversează omul modern" $" 56$.

Corpul devine, astfel, un instrument pe care avangardiștii îl folosesc pentru a reda o sensibilitate a prezentului și neliniștile interioare ale omului totodată. Criza corporalității umane în secolul al XX-lea duce la înstrăinare, întocmai precum afirmă și Adrian Marino: „omul modern este alienat”, ${ }^{\text {, }}$. În consecință, societatea este și ea întocmai, modernă și alienată, iar în cadrul ei, omul conștientizează că este deseori captiv în propriul trup, fie el sănătos, suferind, maladiv sau deformat. Şocul şi corporalitatea etalată ca mecanism vulnerabil și suferind, toate acestea au o strânsă legătură cu obsesia efectelor Primului Război Mondial, perioadă dominată de violență și boală. „Poetul nou e un explorator" ${ }^{\text {,58 }}$, așa cum afirmă Ilarie Voronca în Cicatrizări. Poezia nouă din 1925 - e un explorator al corpului uman pe care îl spectacularizează.

\section{Bibliografie}

Blecher, Max, Intâmplări în irealitatea imediată, Editura Minerva, București, 1970.

Boldea, Iulian, Simbolism, modernism, tradiționalism, avangardă, Editura „Aula", Brașov, 2002.

Buciu, Marian Victor, Panorama literaturii române în secolul XX, I, Editura Scrisul Românesc, Craiova, 2003.

Ciric, Alina-Daniela, Corporalitate și intersubiectivitate, Editura Academiei Române, Cluj-Napoca, 2015.

Corbin, Alain, Courtline, Jean-Jacques, Vigarello, Georges, Istoria corpului, I, traducere din limba franceză de Simona Manolache, Gina Puica, Muguraș Constantinescu, Giuliano Sfichi, Grupul Editorial Art, București, 2008.

Corbin, Alain, Courtline, Jean-Jacques, Vigarello, Georges, Istoria corpului, III, traducere din limba franceză de Simona Manolache, Mihaela Arnat, Muguraș Constantinescu, Giuliano Sfichi, Grupul Editorial Art, București, 2009.

Dinescu, Lucia Simona, Corpul în imaginarul virtual, Editura Polirom, Iași, 2007.

Glăvan, Gabriela, Viraj în ireal. Modernități particulare în literatura română interbelică , Editura Universității de Vest, Timișoara, 2014.

Le Breton, David, Antropologia corpului și modernitatea, traducere de Doina Lica, Editura Amacord, Timişoara, 2002.

\footnotetext{
${ }^{56}$ Alexandru Mușina, op. cit., p. 102.

${ }^{57}$ Adrian Marino, op. cit., p. 196.

${ }^{58}$ Marin Mincu, op. cit., 1983, p. 571.
} 
Marino, Adrian, Biografia ideii de literatură, volumul 6, Editura Dacia, ClujNapoca, 2000.

Mincu, Marin, Avangarda literară românească, Editura Minerva, București, 1983.

Mincu, Marin, Experimentalismul poetic românesc, Editura Paralela 45, Pitești, 2006.

Mușina, Alexandru, Paradigme moderne, Editura „AULA”, Brașov, 2004.

Pană, Sașa, Antologia literaturii române de avangardă, Editura pentru literatură, București, 1969.

Pârlog, Hortensia, Brînzeu, Pia, Pârlog, Aba, Translating the body, Institutul European, Iași, 2009.

Piru, Al., Istoria literaturii române, Editura „Grai și suflet - cultura națională”, București, 1994.

Pop, Ion, Avangardismul poetic românesc, Editura pentru literatură, București, 1969.

Pop, Ion, A scrie și a fi. Ilarie Voronca şi metamorfozele poeziei, ediţia a II-a, Editura Cartea Românească, București, 2007.

Voronca, Ilarie, Poeme alese, I, traduceri și prefață de Sașa Pană, Editura Minerva, București, 1972.

Voronca, Ilarie, Ulise. Brățara nopților, ediție îngrijită de Ion Pop, Editura Dacia, Cluj-Napoca, 2003. 